\title{
Téoros
}

Revue de recherche en tourisme

\section{Le musée du Séminaire de Québec. Un musée qui trace l'histoire, toujours vivante, des francophones en Amérique du Nord}

\section{Robert Malenfant}

Volume 12, numéro 1, mars 1993

Québec, capitale et région touristiques

URI : https://id.erudit.org/iderudit/1078203ar

DOI : https://doi.org/10.7202/1078203ar

Aller au sommaire du numéro

Éditeur(s)

Université du Québec à Montréal

ISSN

0712-8657 (imprimé)

1923-2705 (numérique)

Découvrir la revue

Citer cet article

Malenfant, R. (1993). Le musée du Séminaire de Québec. Un musée qui trace l'histoire, toujours vivante, des francophones en Amérique du Nord. Téoros, 12(1), 43-43. https://doi.org/10.7202/1078203ar 


\section{Le musée du Séminaire de Québec Un musée qui trace l'histoire, toujours vivante, des francophones en Amérique du Nord Robert Malenfant"}

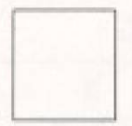

Dès 1663, François de Laval, premier évêque de la Nouvelle-France, jette les bases du Grand Séminaire, voué à la formation des clercs. La démarche d'enracinement dans ce pays neuf se poursuit, avec la fondation en 1668 du Petit Séminaire. Celui-ci forme les fils des colons français qui assureront le développement du continent nouveau.

C'est à partir de ces deux institutions que seront constituées patiemment les collections du musée: livres, journaux d'époque, documents du début du Régime français, animaux naturalisés, instruments scientifiques, gravures, peintures. Ces collections s'enrichissent graduellement des achats effectués par les prêtres du Séminaire aux quatre coins du monde. Aujourd'hui, le Musée augmente ses collections avec les legs et dons qu'il reçoit.

Dès 1806, avec la naissance du Musée scientifique du Séminaire de Québec, débute les activités muséologiques qui se poursuivent toujours. En 1989, devant l'ampleur des collections qui débordent très largement la vocation éducative du Séminaire, pour toucher une grande partie de l'histoire des francophones en Amérique du Nord, le musée réoriente son mandat:

«L'approche musćologique sera d'ordre historique: les lieux, les édifices et les collections seront consacrés à illustrer les artisans de l'histoire, à rappeler ce qu'ils ont accompli dans le but de bâtir le pays et le continent et d'implanter la civilisation française en Amérique du Nord.s

Actuellement, que ce soitl'exposition Les garde-manger de la ville sur lesmarchés publicsau Québec, ou Si la Saint-Jean m'étaitcontée, ou Souvenirsd'Égypte, le Musée duSéminaireremplit son nouveau mandatd'une façon dynamique etmoderne, avec unelarge ouverture sur le monde.

Le Musée du Séminaire, qui deviendraéventuellement le Muséede l'Amérique française, $s$ 'inscrit parfaitement dans l'histoire de la ville deQuébec, luiqui futl'un des points de départetde convergence des francophones en Amérique du Nord et sur d'autres continents. Le titre de capitale de la francophonie, associé à la ville de Québec, constitue un héritage précieux à mettre en valeur et à développer comme le fait si bien le Musée du Séminaire et comme il l'inscrira encore davantage par sa nouvelle appellation de Musée de l'Amérique française.

\footnotetext{
- Monsieur Robert Malenfant est responsable des communications, des relations publiques et de la diffusion au Musée du Seminaire de Ouebec.
}

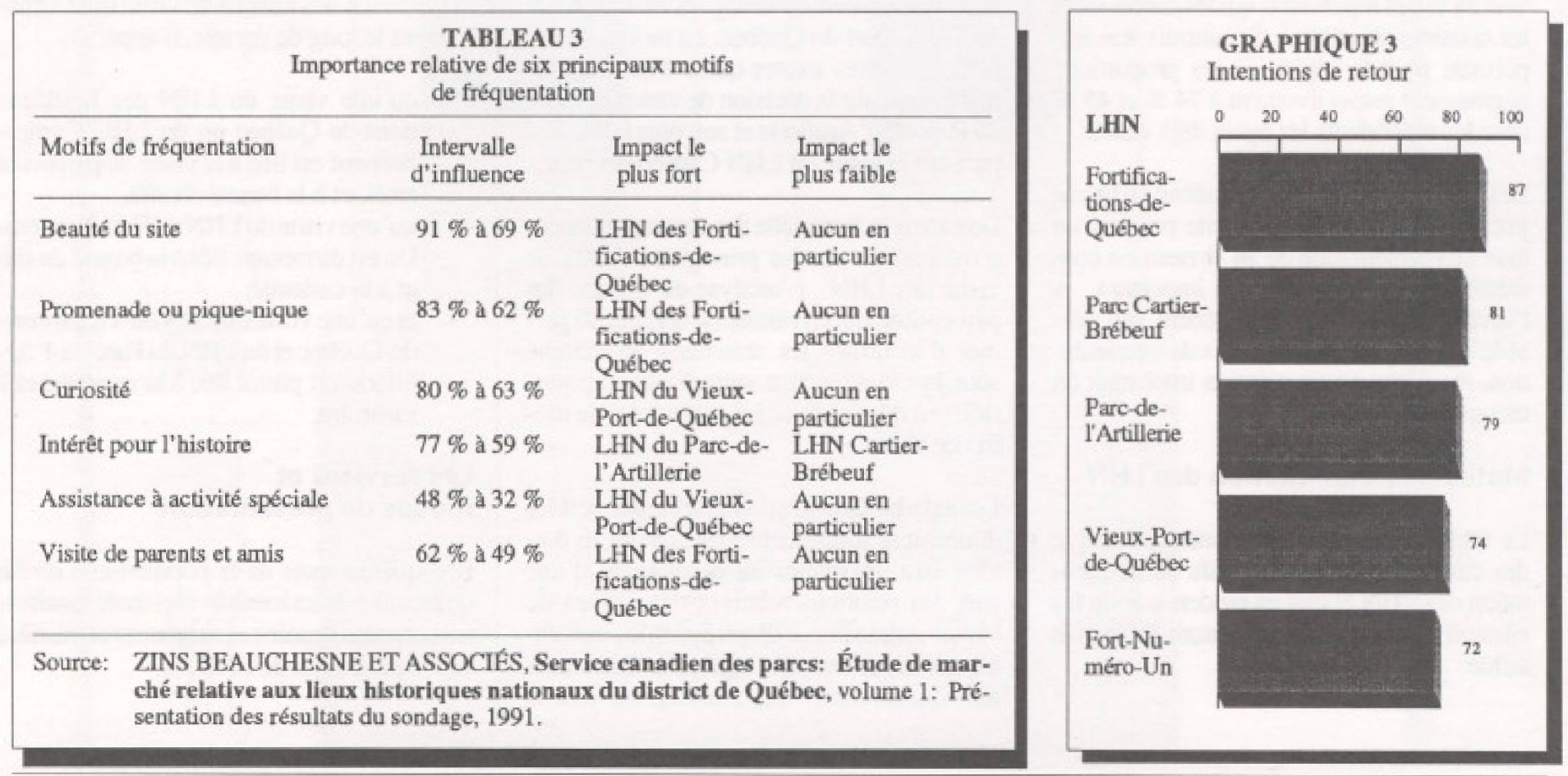

